\title{
Teoria i praktyka celebrytyzacji politycznej. Celebryci polityczni w internetowych serwisach plotkarskich
}

$\mathrm{C}$ elebryci są przedmiotem rosnącego zainteresowania badaczy, publicystów i dziennikarzy. Studia nad sławą, stały się już osobną sferą badań z własnym periodykiem naukowym ${ }^{1}$. Od samego początku celebrity studies, a nawet jeszcze wcześniej ${ }^{2}$ koncepcję celebrity odnoszono również do dziedziny politycznej. Pojawia się już nawet literatura poświęcona wyłącznie celebrytom świata polityki ${ }^{3}$, opisująca zjawisko rosnącej roli sławy we współczesnej polityce w kontekście tabloidyzacji ${ }^{4}$, postpolityki ${ }^{5}$ czy ,urozrywkowienia” polityki ${ }^{6}$. Pomimo rosnącego korpusu literatury z zakresu studiów nad celebrytami politycznymi, dziedzina ta wciąż boryka się z co najmniej dwoma podstawowymi problemami. Pierwsza trudność dotyczy operacyjnego stosowania samej koncepcji celebryty do opisu sfery politycznej. Drugi problem to niewielka liczba ugruntowanych empirycznie analiz zjawiska politycznej celebrytyzacji.

1 Kwartalnik „Celebrity Studies” wydawany jest przez Routledge od 2010 zob. http://www.tandfonline.com/action/aboutThisJournal?journalCode=rcel20.

2 Charles Wright Mills w swojej analizie elit wydanej w 1956 r., a więc przed klasyczną pozycją opisującą celebrytyzację - The Image, Daniela J. Boorstina - poświęca zagadnieniom związków między elitą władzy a światem sław cały rozdział. Zob. tegoż, Elita władzy, Książka i Wiedza, Warszawa 1961.

3 D. M. West, J. M. Orman, Celebrity Politics, Prentice Hall, 2002.

4 D. Piontek, Komunikowanie polityczne i kultura popularna: tabloidyzacja informacji o polityce, Wydawnictwo Naukowe WNPiD UAM, Poznań 2011.

5 O. Annusewicz, Celebrytyzacja polityczna, „Studia Politologiczne” 2011, vol. 20, s. 268-278.

6 T. Olczyk, Przywódca czy celebrity? Strategie kreowania wizerunku $w$ reklamie politycznej, w: Gra w przywództwo - jak zdobyć i utrzymać władzę, red. B. Szklarski, Collegium Civitas Press, Centrum Kreowania Liderów, 2008; T. Olczyk, Politrozrywka i popperswazja: reklama telewizyjna $w$ polskich kampaniach wyborczych XXI wieku, Wydawnictwa Akademickie i Profesjonalne, Warszawa 2009. 
Niniejszy artykuł ma na celu zapoczątkować wypełnianie owej luki. W pierwszej części analizie poddane zostaną problemy terminologiczne związane z pojęciem politycznego celebryty. W dalszej kolejności autor zaproponuje nowe podejście do tego terminu. Oparta na tym ujęciu badawcza część artykułu będzie poświęcona trajektoriom czterech wybranych celebrytów politycznych w serwisach plotkarskich plotek.pl i pudelek.pl.

\section{Celebrity - celebryta, celebrytyzacja}

Pierwszą przeszkodą w badaniu politycznych celebrytów jest nieprecyzyjność samego pojęcia i związane z nią ograniczone możliwości jego stosowania do opisu polityków.

Zaproponowana przez Daniela Boorstina ${ }^{7}$, a rozpropagowana w Polsce przez Wiesława Godzica, definicja mówi, iż celebryci to „ludzie znani z tego, że są znani”. Ujęcie to zwraca uwagę na tautologiczność „celebryckiej” formy sławy i brak jej oparcia na rzeczywistych osiagnięciach. David Marshall - inny często cytowany badacz zjawiska - określa celebrytów jako tych, którzy „za pośrednictwem mass mediów cieszą się większą obecnością i szerszym zakresem możliwości działania i wpływu (agency), niż reszta populacji. Sławom wolno wkraczać na scenę publiczna, podczas gdy reszta może jedynie patrzeć ${ }^{8 ”}$. Oba ujęcia celebryty mają niewątpliwą wartość uczulającą ${ }^{9}$. Pozwalają dostrzec narodziny i rozwój nowej sfery kultury popularnej i rosnącą rolę „klasycznych” celebrytów. Zastosowanie tych definicji do świata polityki jest jednak dość trudne. W erze polityki skoncentrowanej na kandydacie ${ }^{10}$ i prezydencjalizacji ${ }^{11}$, bycie „znanym” jest warunkiem koniecznym bycia politykiem. Z drugiej strony dominacja opartej na marketingu ,post-

7 D. J. Boorstin, The image: a guide to pseudo-events in America, Harper \& Row, Publishers, New York 1964, s. 57.

8 P. D. Marshall, Celebrity and power: fame in contemporary culture, University of Minnesota Press, Minneapolis Minn 1997, s. IX.

9 Więcej o pojęciach uczulających w K. Konecki, Studia z metodologii badań jakościowych: teoria ugruntowana, Wydawnictwo Naukowe PWN, Warszawa 2000, s. $36-38$.

10 Zob. W. Cwalina, Marketing polityczny: perspektywa psychologiczna, Gdańskie Wydawnictwa Psychologiczne, Gdańsk 2005.

11 T. Olczyk, Politrozrywka..., op. cit., s. 118. 
polityki"12 i niewielkie zaangażowanie poznawcze wyborców w proces polityczny ${ }^{13}$ sprawiaja, że politycy znani są ogółowi społeczeństwa w dużym stopniu właśnie „,z tego, że są znani”. „Sława” oparta na ekspozycji medialnej, a nie na realnych osiagnięciach nie stanowi zatem dobrego kryterium odgraniczenia zbioru celebrytów politycznych od całej reszty polityków. Problem ten jest na tyle poważny, że autorzy zajmujący się celebrytami politycznymi wyraźnie unikają kwestii definicyjnych. Najczęściej chyba cytowani Darrell West i John Orman czy John Street koncentrują się raczej na konstruowaniu typologii politycznych celebrytów, oferując domyślne definicje przez wyliczenie ${ }^{14}$.

Dodatkową komplikację powoduje wieloznaczność samego słowa celebrity, od którego pochodzi polski „,celebryta”. Angielskie „celebrity” ma co najmniej dwa znaczenia. Pierwsze z nich można nazwać „osobowym”. W tym ujęciu „celebrity” to osoba o określonym statusie, ciesząca się szczególnego rodzaju sławą czy zainteresowaniem innych, czyli właśnie „celebryta”. „Celebrity” ma jednak również odcień nieosobowy. Słowo to oznaczać może stan bycia znanym, czy specjalny typ sławy. To rozróżnienie ma dość istotne konsekwencje. Osobowe ujmowanie celebrity skłania do postrzegania tego zjawiska w kategoriach binarnych, statusowych i statycznych ${ }^{15}$. To ujęcie usuwa jednocześnie z pola widzenia procesy osiagania i utraty sławy, strategie i praktyki stawania się celebryta, procesualność, płynność i niestabilność zjawiska.

Trudności z zastosowaniem „osobowej” wersji celebrity do badań komunikacji politycznej i zalety nieosobowego ujęcia skłaniają do bliższego przyjrzenia się temu ostatniemu. Nieosobowe rozumienie celebrity, jest w istocie nie jednym, ale całym zbiorem wzajemnie powiązanych znaczeń $^{16}$. Z uwagi na rozmiar i cel artykułu z tego zbioru wybrano trzy,

12 T. Olczyk, Widmo postpolityzmu, w: Platforma Obywatelska: diagnoza, Wyższa Szkoła Promocji: Klub Badań nad Propagandą, Warszawa 2012, ss. 7-28.

$13 \mathrm{Na}$ ten temat zob. np. N. Maliszewski, Jak zaprogramować wyborcę?, Centrum Doradztwa i Informacji „Difin”, Warszawa 2008.

14 D. M. West, J. M. Orman, op. cit., s. 2; J. Street, Celebrity Politicians: Popular Culture and Political Representation, „British Journal of Politics \& International Relations" 2004, no. 6, s. 437-438.

15 A. Marwick, d. boyd, To See and Be Seen: Celebrity Practice on Twitter, „Convergence: The International Journal of Research into New Media Technologies", vol. 17, no. 2, May 2011, s. 140.

16 Szerszy przegląd ,nieosobowych” definicji celebrytów u A. Marwick, d. boyd, op. cit. 
które wydają się kluczowe dla zrozumienia fenomenu politycznego celebryty.

Po pierwsze celebrity można rozumieć jako szczególny rodzaj kapitału. Do tego ujęcia nawiązują badacze marketingu Iriving Rein, Philip Kotler i Martin Stoller ${ }^{17}$. Autorzy ci określają celebrity jako „osobę, której nazwisko ma tendencję do przyciagania uwagi, wzbudzania zainteresowania i generowania zysków"18. Na pierwszy rzut oka definicja ta zalicza się do grupy „osobowych”. Bliższe spojrzenie prowadzi jednak wprost do „kapitałowego" pojmowania celebrity. Osoby znane posiadaja szczególny kapitał, który cytowani autorzy nazywają „wysoką widocznością" (high visibility) ${ }^{19}$. Tak rozumiana celebryckość jest szczególnie pożądanym dobrem, jej dysponenci korzystają z ekonomicznej „premii sławy". Biznesmen, pisarz, artysta czy naukowiec cechujący się celebryckością uzyskuje znacznie wyższe zyski ze swej działalności, niż ich „niewidoczni” koledzy. Celebryckość można spieniężać również bezpośrednio wykorzystując wysoką widoczność celebryty w marketingu i reklamie ${ }^{20}$. Ekonomiczna premia sławy jest według Reina, Kotlera i Stollera główną przyczyną dynamicznego rozwoju ,przemysłu celebryckości" (celebrity industry). Przemysł ten zajmuje się kreowaniem i zarządzaniem fabrykowana, niezwiązaną z talentem czy rzeczywistymi umiejętnościami sławą (manufactured fame) ${ }^{21}$. Pojawia się jednak pytanie dlaczego wysoka widoczność pełni tak istotną rolę ekonomiczną? Jedną z odpowiedzi może stanowić pierwszy człon definicji Reina, Kotlera i Stollera. Celebrity przyciagga uwagę, zwiększa oglądalność, „klikalność", słuchalność itp. Stąd między innymi rosnąca rola celebrytów w ekonomii mediów, które na coraz bardziej konkurencyjnym rynku walczą o uwagę odbiorców. Zainteresowanie konsumentów mediów można coraz skuteczniej analizować, kwantyfikować, a następnie spieniężać sprzedając reklamy. Uwagę traktować można z jednej strony jako inwestycję jaką ponoszą konsumenci celebryckości, z drugiej jako element szerszego zjawiska - szczególnej relacji jaka łączy celebrytę i jego konsumentów. Ten punkt prowadzi do drugiego $\mathrm{z}$,nieosobowych” ujęć celebrity.

17 I. J. Rein i in., High visibility, Dodd, Mead, Nowy Jork 1987.

18 Ibidem, s. 14.

19 Ibidem, s. 15.

${ }^{20}$ Zob. np. R. Niczewski, J. Potrzebowski, Celebryci w ataku: celebrity effect jako skuteczne narzędzie komunikacji marketingowej, Agora, Warszawa 2010.

${ }^{21}$ I. J. Rein i in., op. cit., s. 14. 
Elizabeth Currid-Haklett ${ }^{22}$ wskazuje na tę szczególną relację jako esencję definicji celebryckości. Jej zdaniem celebrity jest „specjalną własnością, jaką posiadają niektóre jednostki, własnością, która sprawia, że społeczeństwo troszczy się (to care) o nie bardziej, niż o innych ludzi" ${ }^{23}$. Angielskie care należy tutaj rozumieć jako zaangażowanie poznawcze, emocjonalne i behawioralne konsumentów czy raczej fanów w relację z celebrytą. Siła tego zaangażowania i jego skala jest podstawą perswazyjnych sukcesów celebrytów. To dzięki relacji z fanami celebryci są w stanie tak skutecznie przekonywać do zakupu określonych produktów czy głosowania na określoną partię polityczną.

Trzecia z nieosobowych definicji celebrity zwraca uwagę na sposób budowania owej szczególnej relacji. Marwick i boyd definiują celebrity jako „organiczną i podlegającą nieustannym zmianom praktykę performatywną". Praktyka ta obejmuje m.in. utrzymywanie bazy fanów za pomocą konstruowanej autentyczności i odgrywanej intymności ${ }^{24}$. Działania te - analizując zachowania celebrytów na Twitterze ${ }^{25}$ - badaczki opisują za pomocą metafory teatralnej Goffmana. Celebrytyzacja jest w tym rozumieniu szczególną formą autoprezentacji.

Klasyczne, goffmanowskie podziały scena-kulisy czy aktorzy-widownia, które dają się obronić przy komunikacji za pomocą Twittera stają się jednak płynne w związku z udziałem mediów w procesie celebrytyzacji. W zależności od tego jakie role przyjmują media i celebryci można wyróżnić dwa aspekty celebrytyzacji. Autocelebrytyzacja czy „celebrytzowanie się" to samodzielne, aktywne działania podmiotu mające na celu budowę celebryckiej relacji z widownią. Drugi aspekt celebrytyzacji ma charakter zewnętrzny. Polityk może być celebrytyzowany przez media poza własną kontrolą, czy nawet wbrew woli. Owe wymiary mogą opisywać różne kombinacje relacji kooperacyjnych i antagonistycznych między mediami a celebrytami.

Produkt interakcji między celebrytą a mediami można określi mianem trajektorii celebrytyzacji. Trajektorię opisuje się w socjologii jako strukturę procesową, przebieg jakiegoś doświadczanego przez aktorów

22 E. Currid-Halkett, Starstruck: the business of celebrity, $1^{\text {st }}$ ed., Faber and Faber, New York 2010.

23 Ibidem, s. 6.

24 A. Marwick, d. boyd, op. cit., s. 140.

25 Twitter jest platformą mikroblogową pozwalającą na wysyłanie i otrzymywanie krótkich wiadomości tekstowych do i od innych użytkowników serwisu. 
społecznych zjawiska i jego zmiany w czasie, fazy, punkty zwrotne oraz działania wywołujące te $z$ miany ${ }^{26}$. Pojęcie trajektorii wydaje się bardziej przydatne od częściej stosowanego w przypadku celebrytów cyklu ży$\mathrm{cia}^{27}$. Trajektoria inaczej niż cykl życia kładzie nacisk na interakcyjne kształtowanie procesu, rolę sił znajdujących się poza kontrolą podmiotu i trudność w przewidywaniu jej ostatecznego przebiegu, odrzuca automatyzm i podkreśla trudność w wyłaniania się zjawisk ${ }^{28}$.

Trajektoria celebrytyzacji oznaczałaby proces stawania się celebrytą i jego przebieg w czasie, oraz przestrzeni opisanej przez takie wymiary jak np. siła i skala relacji celebryta-widownia, wizerunek celebryty i jego ekspozycja medialna itp., itd. Opis pełnej trajektorii nawet pojedynczego celebryty wykracza oczywiście poza rozmiary tego artykułu. W niniejszym artykule przeanalizowane zostaną zatem wycinki trajektorii wybranych celebrytów w czasie i „przestrzeni”. „Przestrzenią” badania będą serwisy plotkarskie Plotek i Pudelek. Badanie obejmie artykułu opublikowane w tych serwisach od stycznia 2007 do maja 2012 roku.

W niniejszym artykule analizie poddano trajektorie celebrytyzacji Donalda Tuska, Jarosława Kaczyńskiego, Katarzyny Tusk i Marty Kaczyńskiej. Dwa pierwsze nazwiska na liście nie wymagają długiego uzasadnienia. Trudno znaleźć bardziej znaczących polityków polskich w okresie funkcjonowania serwisów plotkarskich. Dodatkowo Tusk i Kaczyński sprawowali podobne funkcje (premier, lider opozycji, kandydat na prezydenta), co daje możliwość porównywania jak podobne aspekty ich biografii wpływały na trajektorie celebrytyzacji.

Dłuższego uzasadnienia wymagają osoby Marty Kaczyńskiej i Kasi Tusk. Dlaczego do celebrytów politycznych zaliczać osoby niepełniące żadnych funkcji politycznych? Marta Kaczyńska i Kasia Tusk należą do opisanej przez Ormana i Westa podgrupy celebrytów politycznych określanych mianem „dziedziczących” (legacies) ${ }^{29}$. Córkę Lecha Kaczyńskiego można zaliczyć także do grupy celebrytów wydarzeniowych ${ }^{30}$.

26 K. Konecki, op. cit., s. 43.

27 Pojęcie cyklu życia w stosunku do celebrytów stosują np. Maciej Mrozowski (tegoż, Bohater naszych czasów, „Kultura Popularna” 2004, nr 3, s. 78-83) i cytowani już Rein, Kotler i Stoller.

${ }^{28}$ K. Konecki, ibidem.

29 D. M. West, J. M. Orman, op. cit., s. 2-3. Według Westa i Ormana celebryci dziedziczący to dzieci i małżonkowie znanych polityków.

30 Ibidem, s. 4. Celebryci wydarzeniowi to zazwyczaj osoby, które uzyskują silną ekspozycję medialną w wyniku udziału w szeroko relacjonowanym zdarzeniu. 
Jak widać na rysunkach 1 i 4 to katastrofa smoleńska i pogrzeb pary prezydenckiej stanowiły kluczowy punkt zwrotny jej celebryckiej kariery, przyciagając jednocześnie uwagę mediów i zainteresowanie publiczności. Drugi argument za badaniem celebrytyzacji tych właśnie postaci to ich funkcjonowanie na pograniczu świata polityki i czystej kultury popularnej. Ta „graniczność” umożliwia porównanie z bardziej typowymi politykami-celebrytami i identyfikację specyfiki celebrytyzacji politycznej. Dodatkowo, podobnie jak w przypadku Donalda Tuska i Jarosława Kaczyńskiego w biografiach Marty Kaczyńskiej i Kasi Tusk występują pewne zbieżności, ale także ciekawe różnice ${ }^{31}$, które pozwalają na porównywanie podobieństw i różnic trajektorii celebrytyzacji.

Kolejny istotny argument za wyborem tej właśnie czwórki to analiza uwagi poświęcanej politykom i ich rodzinom oparta na Google Trends $(\mathrm{GT})^{32}$. Mówiąc krótko narzędzie to pozwala sprawdzać jakie słowa użytkownicy Internetu wpisują w okno wyszukiwarki Google, tym samym daje wyobrażenie o skali i dynamice poznawczych inwestycji publiczności w relacje z celebrytami (jeśli to ich nazwiska są owymi hasłami). Dynamikę zainteresowania internautów wybranymi do analizy celebrytami ukazuje wykres nr 1. Wstępna analiza porównawcza wykazała, iż to właśnie Donald Tusk i Jarosław Kaczyński byli politykami cieszącymi się największym zainteresowaniem mierzonym za pomocą GT. W kategorii „znani członkowie rodzin polityków” pierwsze miejsca zajęły Marta Kaczyńska i Kasia Tusk ${ }^{33}$. Z uwagi na specyfikę prezentowania danych przez $\mathrm{GT}^{34}$ dla lepszego zobrazowania jako porównanie dodano statystykę wyszukiwań „niepolityczną” celebrytkę Dodę.

Osoby te zyskują przy okazji szczególną wiarygodność w kwestiach powiązanych z owym celebrytyzującym wydarzeniem.

31 Wyliczając podobieństwa obu par celebrytów nie można jednak zapomnieć o różnicach obu par celebrytów takich jak: wiek, wizerunek, stan cywilny, relacje rodzinne i oczywiście poglądy polityczne itp., itd.

32 Więcej informacji o Google Trends na stronie http://support.google.com/ trends/?hl=en-US.

33 Hasło „Weronika Rosati” było według Google Trends częściej poszukiwanym przez internautów. Córka Dariusza Rosatiego w momencie powstania serwisów plotkarskich znajdowała się już na takim etapie trajektorii celebrytyzacyjnej, w którym to raczej Dariusz Rosati „dziedziczył” jej celebryckość. Stąd też nie znalazła się na liście analizowanych postaci.

34 Dane Google Trends są ukazywane nie w liczbach bezwzględnych, ale relatywnie. 


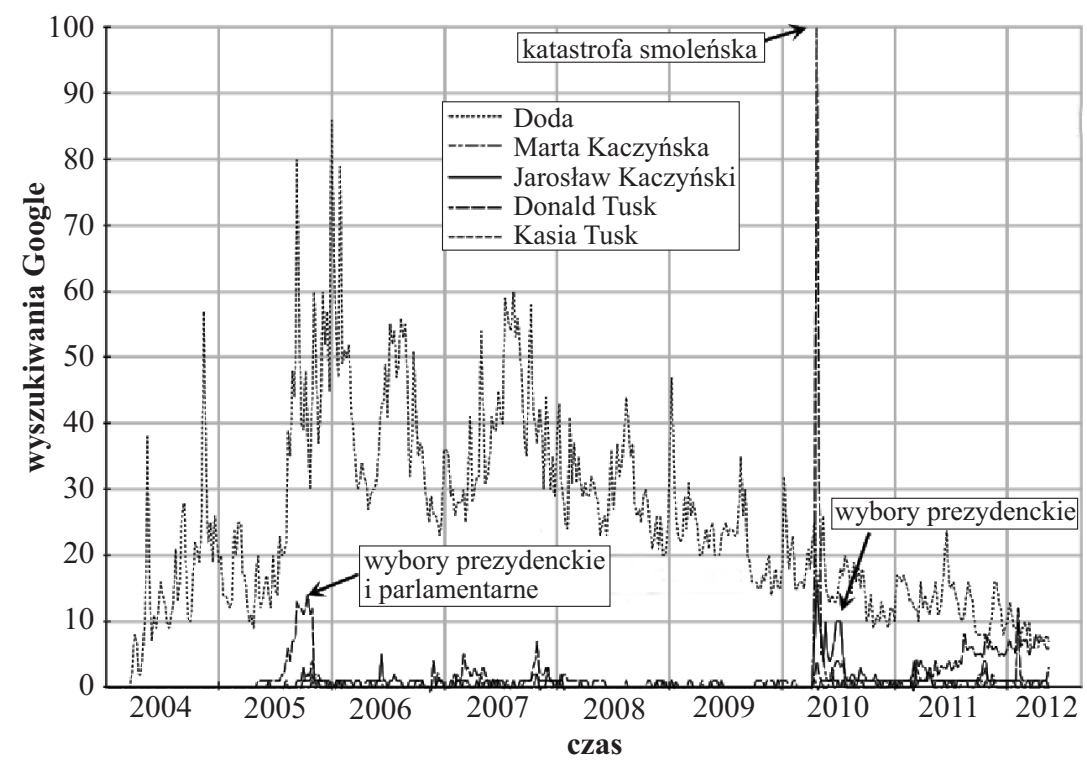

Rys. 1. Dynamika zainteresowania celebrytami politycznymi mierzona trendami wyszukiwania w Google

Przedmiotem analizy niniejszego rozdziału są trajektorie wymienionej czwórki politycznych celebrytów $\mathrm{w}$ internetowych serwisach plotkarskich. Serwisy tego typu są interesującym polem badania procesów celebrytyzacji z uwagi na podkreślane przez badaczy postępujące „,urozrywkowienie" Internetu ${ }^{35}$. Jednocześnie serwisy plotkarskie są ściśle wyspecjalizowane $\mathrm{w}$ produkowaniu i sprzedawaniu informacji o celebrytach. Wydają się najlepiej spełniać definicję tego co Street nazywa „kanałem komunikacji typowym dla celebrytów” "36.

W artykule przeanalizowano zawartość dwóch takich serwisów: Pudelek i Plotek. Wybór tych właśnie witryn był podyktowany trzema czynnikami. Po pierwsze Pudelek i Plotek to najstarsze serwisy plotkarskie. Pudelek powstał w styczniu 2006 roku, Plotek dziewięć miesięcy później ${ }^{37}$. Badanie pozwoliło zatem przyjrzeć się trajektoriom z najdłuższej możliwej perspektywy. W przypadku Kasi Tusk i Marty Kaczyń-

35 A. Garapich, Wpatrzeni w gwiazdy, „Press”, nr 155, grudzień 2008, s. 76.

J. Street, op. cit., s. 437-438.

37 A. Garapich, op. cit., s. 76. 
skiej umożliwiło to uchwycenie trajektorii celebrytyzacji niemal od wejścia na scenę publiczną.

Po drugie Plotek i Pudelek należą do najbardziej popularnych portali tego rodzaju. W badaniu PBI serwisy te wskazywane były jako ulubione serwisy plotkarskie internautów (odpowiednio 48\% i 16\% wskazań) ${ }^{38}$. Po trzecie zaś, wstępna analiza wykazała, że są one względnie bogatsze w informacje o celebrytach politycznych niż inne popularne serwisy plotkarskie.

Artykuły w obu serwisach charakteryzowały się podobną formą: niewielką ilością tekstu, któremu zawsze towarzyszyło co najmniej jedno zdjęcie. W obu serwisach stosowano bardzo charakterystyczny zabieg wizualny, polegający na zestawianiu zdjęć celebrytów, gdy artykuł traktował o relacji między nimi. Artykuły zazwyczaj składały się z krótkiej informacji, najczęściej cytatu z innego medium, bardzo często zwierały komentarze i oceny. Często również pojawiały się różnego rodzaju zachęty do komentowania i brania aktywnego udziału w dyskusji pod zamieszczanymi artykułami. Niekiedy, szczególnie w przypadku rankingów i porównań celebrytów, artykuły przybierały formę „pokazu slajdów": serii klikanych po kolei zdjęć z krótkimi podpisami. Nieco więcej miejsca specyfice ramowania ${ }^{39}$ serwisów plotkarskich poświęcono $\mathrm{w}$ ostatniej części artykułu.

Celem analizy ilościowej było przede wszystkim zbadanie dynamiki zainteresowania wybranymi celebrytami politycznymi przez serwisy plotkarskie, a także analiza kontekstu w jakim owi celebryci się pojawiali. Artykuły zakodowano zatem według daty, głównego bohatera i kategorii tematycznej. Z uwagi na objętość artykułu w analizie ukazano 12 najczęściej pojawiających się kategorii tematycznych. W większości przypadków artykułowi przypisywano jeden kod tematyczny, jednak zdarzały się przypadki dwóch lub trzech kodów. Pierwsze artykuły na temat wymienionej czwórki celebrytów ukazały się na początku 2007 roku. Proces zbierania artykułów zakończono w maju 2012 roku. W badanym zbiorze znalazły się wszystkie opublikowane w tym okresie artykuły na temat opisanej czwórki celebrytów wyszukane za pomocą wewnętrznych wyszukiwarek serwisów ${ }^{40}$. Wyniki tej analizy ukazuje tabela 1 .

38 Ibidem.

39 Na temat ramowania i analizy ramowej więcej w T. Olczyk, Politorozrywka..., op. cit., s. 229-279.

40 Wyszukiwarki (szczególnie Pudelka) pokazują większą liczbę artykułów na temat opisanych postaci niż rzeczywiście znajdujące się w serwisach plotek i pude- 
W tej części artykułu opisane zostaną główne wnioski z ilościowej analizy artykułów na temat wybranych celebrytów (tabela 1). Pierwsza interesująca obserwacja dotyczy różnic w liczbie artykułów na temat poszczególnych bohaterów. Analiza ukazuje wyraźną przewagę obu celebrytek „dziedziczących”, a szczególnie Kasi Tusk. Ten wynik nie jest szczególnie zaskakujący w kontekście profili serwisów i ich użytkowników. Interesująca jest jednak ostatnia pozycja Donalda Tuska na tej liście.

Tabela 1

Artykuły na www.plotek.pl i www.pudelek.pl od 01.2007 do 05.2012

\begin{tabular}{|c|c|c|c|c|c|c|c|c|}
\hline Bohater & \multicolumn{2}{|c|}{$\begin{array}{l}\text { Jarosław } \\
\text { Kaczyński }\end{array}$} & \multicolumn{2}{|c|}{ Donald Tusk } & \multicolumn{2}{|c|}{$\begin{array}{c}\text { Marta } \\
\text { Kaczyńska }\end{array}$} & \multicolumn{2}{|c|}{ Kasia Tusk } \\
\hline Suma artykulów & \multicolumn{2}{|c|}{89} & \multicolumn{2}{|c|}{60} & \multicolumn{2}{|c|}{121} & \multicolumn{2}{|c|}{244} \\
\hline $\begin{array}{l}\text { Tematyka } \\
\text { artykulów }\end{array}$ & liczba & odsetek & liczba & odsetek & liczba & odsetek & liczba & odsetek \\
\hline Konflikt & 33 & $37,08 \%$ & 6 & $10,00 \%$ & 32 & $26,45 \%$ & 20 & $8,20 \%$ \\
\hline Kpina i żart & 14 & $15,73 \%$ & 7 & $11,66 \%$ & 1 & $1,21 \%$ & 15 & $6,14 \%$ \\
\hline Lans & 6 & $6,74 \%$ & 14 & $23,33 \%$ & 16 & $13,22 \%$ & 129 & $52,87 \%$ \\
\hline Luksus & 3 & $3,37 \%$ & - & - & 14 & $11,57 \%$ & 4 & $1,64 \%$ \\
\hline $\begin{array}{l}\text { Pozytywna relacja } \\
\text { z innym celebrytą }\end{array}$ & 4 & $4,49 \%$ & 7 & $11,67 \%$ & 6 & $4,96 \%$ & 7 & $2,87 \%$ \\
\hline Ranking & 6 & $6,74 \%$ & 8 & $13,33 \%$ & 6 & $4,96 \%$ & 24 & $9,84 \%$ \\
\hline Seks & 2 & $2,25 \%$ & 4 & $6,67 \%$ & 2 & $1,65 \%$ & 4 & $1,64 \%$ \\
\hline Pogrzeb, żałoba & 2 & $2,25 \%$ & 2 & $3,33 \%$ & 19 & $15,70 \%$ & - & - \\
\hline Wpadka & 9 & $10,11 \%$ & 5 & $8,33 \%$ & - & - & 6 & $2,46 \%$ \\
\hline Wybory & 9 & $10,11 \%$ & 4 & $6,67 \%$ & 8 & $6,61 \%$ & 5 & $2,05 \%$ \\
\hline Związek & 7 & $7,87 \%$ & - & - & 25 & $20,66 \%$ & 30 & $12,30 \%$ \\
\hline Zwykłe życie & 2 & $2,25 \%$ & 3 & $5,00 \%$ & 3 & $2,48 \%$ & 38 & $15,57 \%$ \\
\hline
\end{tabular}

Do pierwszej z ukazanych w tabeli kategorii tematycznych zaliczono artykuły, które opisywały relacje antagonistyczne głównego bohatera z innymi postaciami. Antagonistami byli tu przede wszystkim inni celebryci, niekiedy politycy czy rodzina lub partnerzy. Jak widać konflikt

lek. Wyszukiwarka pudelka umieszcza na liście artykuły z serwisów Kotek i Kozaczek, niekiedy jako artykuły opisujące danego celebrytę wskazywane były artykuły zawierające jedynie link do artykułu o wyszukiwanej postaci. W kilku przypadkach nie udało się otworzyć sygnalizowanych przez wyszukiwarkę tekstów. 
jest dość istotną kategorią celebrytyzującą w przypadku serwisów plotkarskich. Jak widać z tabeli 1, konflikt jest częstym tematem artykułów opisujących Jarosława Kaczyńskiego i Martę Kaczyńską.

Kolejny temat artykułów wart dłuższego komentarza to kpina i żart. Serwisy plotkarskie bardzo często przyjmują rolę arbitra, sędziego, a czasem kpiarza. Oceniają, recenzują bądź wyśmiewają opisywanych celebrytów. W tej kategorii znalazły się też artykuły opisujące żarty internautów z celebrytów (obrazy, filmy czy wypowiedzi na forach). Artykuły zawierające żarty z celebrytów są rzadsze od tych opisujących ich konflikty, jednak jak się wydaje jest to kolejna kategoria, o którą można poszerzyć boorstinowską listę celebrytyzujących tematów ${ }^{41}$. Kategoria ta jest także przejawem skomplikowanej i ambiwalentnej relacji portali plotkarskich i celebrytów. Szczególnie częstym obiektem kpin w serwisach plotkarskich był Jarosław Kaczyński. W przypadku Kasi Tusk tę kategorię wypełniły głównie kpiące recenzje jej „drewnianego" stylu tanecznego w „Tańcu z Gwiazdami”, a później cytaty z parodiującej jej blog strony „MakeLifeHarder”.

Serwisy plotkarskie skrzętnie odnotowują i komentują pojawianie się celebrytów na okładkach kolorowych pism, w celebryckich programach telewizyjnych czy ich działania autocelebrytyzujące jak wpisy na blogu czy profilach w serwisach społecznościowych. Opisując tego rodzaju działania Plotek i Pudelek dość często używają rzeczownika „lans” i czasownika „lansować się”, stąd też jego użycie w kluczu kodowym. Jak widać w „lans” jest tematem ponad połowy artykułów o Kasi Tusk i relatywnie dużej (w porównaniu do Jarosława Kaczyńskiego) liczby artykułów od Donaldzie Tusku. Wydaje się, że premier, a szczególnie jego córka, bliżsi są klasycznym celebrytom, dla których to właśnie „lans” jest podstawową aktywnością.

„Luksus” obejmuje wszelkie artykuły, których głównym tematem są przejawy bogactwa celebrytów (kosztowne domy i mieszkania, samochody, służba, ochrona, markowe ubrania, gadżety itp., itd.). Kategoria ta ilustruje typowe dla świata celebrytów zjawisko dystansu od „zwykłego człowieka". W tej kategorii dość zaskakująca jest wysoka pozycja Marty Kaczyńskiej i jej stryja. Jak widać Tuskowie, mimo celebryckiego „lansu”, nie kojarzą się serwisom plotkarskim z bogactwem i luksusem.

41 D. J. Boorstin, op. cit., s. 65. 
Ranking jest dość typowym formatem dla serwisów plotkarskich. Treścią rankingu są wszelkiego rodzaju rankingi, sondaże i porównania celebrytów. Format ten zazwyczaj sprowadza się do serii pojedynczych zdjęć i bardzo krótkich opisów celebrytów. Jak widać ten format pojawia się częściej w artykułach dotyczących Kasi Tusk i jej ojca.

Jak pisze David Marshall, utrzymywanie statusu wymaga od celebryty ciągłego balansowania pomiędzy dystansem i niezwykłością a bliskością i podobieństwem w stosunku do odbiorcy ${ }^{42}$. Konteksty takie jak „lans”, „luksus” czy wszelkiego rodzaju rankingi ukazują politycznych celebrytów w odległym świecie gwiazd. Kategorią, która ukazuje ich intymne życie i przybliża zwykłemu konsumentowi jest „związek”. Pod tym terminem kryją się wszelkiego rodzaju miłosno-romantyczne perypetie celebrytów. Serwisy plotkarskie dość często opisują owe relacje w przypadku Marty Kaczyńskiej i Kasi Tusk, ale również Jarosława Kaczyńskiego.

Do bliskości i podobieństwa odwołuje się kategoria „zwykłe życie”. Plotek i Pudelek dość często relacjonują bardzo ,zwyczajne” czynności sławnych ludzi. W przypadku opisywanych celebrytów politycznych, są to zakupy na bazarku, praca w ogródku, lekcje jazdy samochodem, nauka na studiach itp. Jak widać w powyższej tabeli artykułu o zwykłym życiu szczególnie często pojawiają się w odniesieniu do Kasi Tusk. Relatywnie częste pojawianie się córki premiera w kontekście „Zwykłego życia" wydaje się sprzeczne z jej typowo celebryckim profilem (duża liczba artykułów o „lansie”).

Kolejna część analizy poświęcona zostanie dynamice ekspozycji poszczególnych celebrytów w serwisach plotkarskich i zmianom kontekstów, w jakich się pojawiają w czasie.

Czasowe ujęcie trajektorii kandydata wyraźnie wskazuje na nasilenie informacji na jego temat w serwisach plotkarskich w okresie kampanii wyborczej i wyborów prezydenckich. Relatywnie dużo miejsca - jak na kawalera - serwisy plotkarskie poświęcają jego relacjom intymno-romantycznym. Większość owych artykułów poświęcone jest jego rzekomemu związkowi z Jolantą Szczypińską, o którym nieco więcej w dalszej części artykułu. To co przede wszystkim wydaje się dominować w celebryckim obrazie Jarosława Kaczyńskiego, to konflikt. Warto tutaj także odnotować, iż Jarosław Kaczyński w większości przypadków nie jest

42 P. D. Marshall, op. cit., s. 227. 




Rys. 2. Trajektoria Jarosława Kaczyńskiego w serwisach Plotek i Pudelek od 01.2007 do $05.2012^{43}$

stroną atakująca, ale atakowaną. Stroną inicjującą owe ataki są przede wszystkim różnego rodzaju „klasyczni celebryci”. W przypadku Jarosława Kaczyńskiego owe ataki są jednocześnie najbardziej agresywne, spośród opisywanej czwórki. Kategoria, konfliktu zdaje się „zarażać” powiązane z celebrytą osoby i ,promieniować” na inne sfery aktywności (związek, rodzina). Po okresie kampanii serwisy plotkarskie zaczynaja informować o konflikcie byłego premiera z bratanicą i jej mężem. Konflikt staje się także istotną kategorią w przypadku Marty Kaczyńskiej, która według portali plotkarskich jest skonfliktowana ze stryjem i własnym mężem.

O Jarosławie Kaczyńskim pisze się na serwisach plotkarskich także w kontekście różnego rodzaju wpadek, a szczególnie gaf ilustrujących inność - obcość kandydata.

Obraz Donalda Tuska w serwisach plotkarskich jawi się jako pozbawiony wyraźnych cech charakterystycznych. Lider PO wydaje się dużo bliższy typowemu celebrycie niż Jarosław Kaczyński. Relatywnie często serwisy plotkarskie umieszczają go w rankingach bądź też opisują jego działania autopromocyjne. Co ciekawe, również inaczej niż w przy-

${ }^{43} \mathrm{Na}$ wszystkich wykresach przyjęto to samo maksimum na osi rzędnych, dla lepszego porównania danych. 


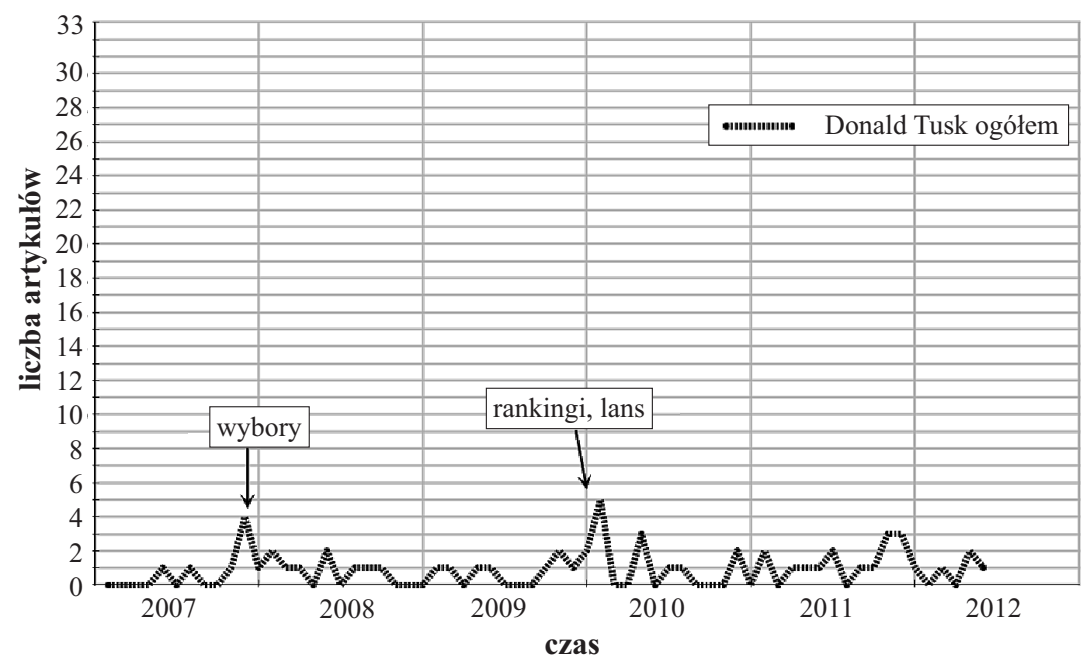

Rys. 3. Trajektoria Donalda Tuska w serwisach Plotek i Pudelek od 01.2007 do 05.2012

padku szefa PiS szczyt widoczności premiera obecnego rządu nie przypada na wybory i okres kampanii. W trajektorii lidera koalicji rządzącej brak jednak widocznych punktów zwrotnych.



Rys. 4. Trajektoria Marty Kaczyńskiej w serwisach Plotek i Pudelek od 01.2007 do 05.2012 
Marta Kaczyńska, staje się widoczna realnie w momencie katastrofy smoleńskiej i kwestii związanych z żałobą. 19 spośród 124 artykułów na temat Marty Kaczyńskiej odnosi się do żałoby po tragicznie utraconych rodzicach. Ta liczba jest interesująca wobec zaledwie dwóch artykułów na ten temat w zbiorze notek, których głównym bohaterem jest Jarosław Kaczyński. W tym okresie serwisy plotkarskie wyraźnie stają niejako po jednej stronie z córką prezydenta. Marta Kaczyńska jest opisywana w kontekście pogrzebu i żałoby, ukazywana jako „zwykła dziewczyna”. W trakcie kampanii prezydenckiej daje o sobie znać typowa dla trajektorii utrata kontroli nad tożsamością (w tym przypadku jej odpowiednikiem jest wizerunek medialny). Już w czasie wyborów prezydenckich dominującą kategorią staje się „lans”, a przede wszystkim wywiady i sesje zdjęciowe dla pism kolorowych, których elementy są wielokrotnie wykorzystywane w różnych kontekstach. W tym czasie głównym tematem artykułów, których bohaterką jest Marta Kaczyńska staje się „luksus”. Serwisy plotkarskie rozpisują się na temat drogich samochodów, które Marta Kaczyńska i jej mąż lubią często zmieniać, mieszkań i domów, które ma posiadać, zakupów w „luskusowych” delikatesach, prywatnych szkół, do których uczęszczają dzieci itp. Bratanica lidera PiS przestaje być bliską odbiorcy „zwykłą dziewczyną" a staje się (niezasłużenie?) bogatą „gwiazdą”, która co gorsza „udaje biedną”.

Po luksusie, dość istotną dla obrazu Marty Kaczyńskiej w serwisach plotkarskich kategorię stanowi wspomniany już konflikt. Serwisy plotkarskie nieustannie spekulują na temat rychłego rozstania Kaczyńskiej z mężem i jej konfliktów ze stryjem.

Gwałtowna zmiana kontekstu ukazywania Marty Kaczyńskiej mogła mieć pewien związek z innym niż Kasia Tusk kierunkiem działań podejmowanych w ,punktach zwrotnych” trajektorii. Pomimo spekulacji córka prezydenta nie wystapiła - inaczej niż premierówna - w „Tańcu z Gwiazdami”. Córka Lecha Kaczyńskiego jednoznacznie wsparła jego brata w kampanii prezydenckiej. Plotkarskie relacje o udziale Kasi Tusk w wyborach sprowadzały się do opisu stroju w jakim odwiedziła lokal wyborczy. Blog Marty Kaczyńskiej inaczej niż blog Kasi Tusk miał jednoznacznie polityczny profil itp., itd.

Celebrytyzacja Kasi Tusk jest jak już wspomniano produktem ubocznym wykorzystania jej wizerunku w kampanii prezydenckiej Donalda Tuska. Inaczej jednak niż Marta Kaczyńska, Kasia Tusk podjęła działania autocelebrytyzacyjne typowe dla klasycznych celebrytów. Efekt ta- 


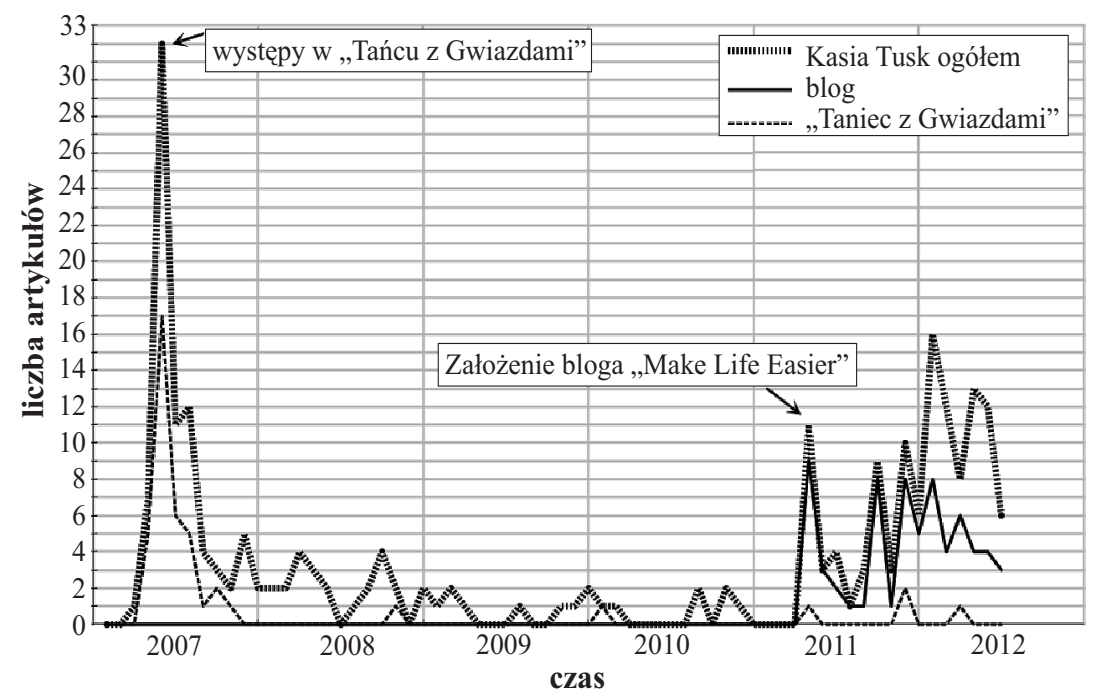

Rys. 5. Trajektoria Kasi Tusk w serwisach Plotek i Pudelek od 01.2007 do 05.2012

kich decyzji wyraźnie widać na rysunku 5. Kasia Tusk stanowi przykład celebrytki idealnej w wielu różnych sensach tego słowa.

Pomimo, że posługując się typologią Westa i Ormana należy zaliczyć córkę premiera do politycznych celebrytów „dziedziczących”, to jej obraz w serwisach plotkarskich jest bardzo bliski wizerunkowi klasycznej, „niepolitycznej” celebrytki. Punktem zwrotnym trajektorii jest w tym przypadku udział w „Tańcu z gwiazdami”, który zapewnia Kasi Tusk krótkotrwałą, ale zarazem największą spośród opisywanych widoczność w serwisach plotkarskich. Owa ekspozycja nie jest później wzmacniana przez żadne nowe zdarzenia w związku z czym zainteresowanie portali Kasią Tusk powoli wygasa. Córka lidera koalicji staje się coraz częstszą bohaterką Plotka i Pudelka wraz z założeniem przez nią modowego bloga „MakeLifeEasier”. Informacje o kolejnych wpisach na blogu stopniowo dominują trajektorię Kasi Tusk. Dwa kolejne tematy, w których kontekście pojawia się Kasia Tusk, to również jak się wydaje typowe dla klasycznych celebrytów kategorie związku i różnego rodzaju typowe dla serwisów plotkarskich rankingi. Co ciekawe drugim najczęściej powtarzającym się tematem w artykułach o Kasi Tusk jest zwykłe życie: zakupy na bazarku, praca ekspedienki w butiku, studia i egzaminy itp. Obraz Kasii Tusk inaczej niż Marty Kaczyńskiej zachowuje zatem równowagę 
w owym opisywanym przez Marshalla ${ }^{44}$ napięciu bliskością a dystansem do przeciętnego konsumenta świata celebrytów towarzyszy gwiazdom.

Córka premiera jest ,idealną” celebrytką także z perspektywy ekonomii serwisów plotkarskich. Portale tego typu bazują w dużej mierze na gotowych treściach, zamieszczanych w innych mediach. Fragmenty informacji medialnych uzyskanych z innych źródeł są następnie ramowane przez portale plotkarskie, zgodnie z typową dla nich „epistemologią” i linią redakcyjną. Kasia Tusk, szczególnie w ostatnim okresie swojej trajektorii celebryckiej dostarcza owych treści nieustannie i za darmo za pośrednictwem swojego bloga.

Dla zrozumienia procesów celebrytyzacji w portalach plotkarskich koniecznych jest kilka bardziej jakościowych obserwacji na temat specyfiki tych mediów. To co wydaje się stanowić szczególną własność serwisów plotkarskich, to zdolność do wydłużania cyklu życia newsów. Dobrym przykładem jest tutaj niewątpliwie cykl informacji o „związku” między Jarosławem Kaczyńskim a Jolantą Szczypińską (por. rys 2). Seria takich informacji pojawia się w maju 2007 na Plotku. Informacja o rzekomym romansie, którą zresztą sam portal już w pierwszym artykule określa jako nieprawdziwą jest jednak powielana w dwóch kolejnych notkach. Temat rzekomego związku między posłanką Szczypińską a liderem PiS powraca po wyborach parlamentarnych. Plotek informuje wtedy o „końcu miłości” między Jarosławem Kaczyńskim a Jolantą Szczypińską. „Koniec miłości” nie oznacza jednak końca życia newsu o owej miłości. Informacja ta pojawia się raz jeszcze, w typowym dla serwisów plotkarskich formacie zestawieniu ,największych rozstań roku”.

Powiązana ze wspomnianą już ekonomią konstruowania informacji jest technika konstruowania artykułów o celebrytach, którą można określić mianem bricolage'u. Pisząc o idolu, a więc specyficznej podkategorii celebryty Maciej Mrozowski zauważa iż ,idola kleci się [...] na zasadzie bricolage'u i marketingu z rekwizytów konwencji i symboli zastanych, poszukując takiej ich kombinacji, którą zachwyci się znaczący krąg odbiorców" ${ }^{45}$. Serwisy plotkarskie klecą bohaterów swoich artykułów przede wszystkim z materiałów zamieszczanych w innych mediach. Najlepszym przykładem może być dwunastokrotne użycie tej samej okładki

\footnotetext{
44 Ibidem.

45 M. Mrozowski, op. cit., s. 82.
} 
jednego z pism kolorowych. Te same zdjęcia, cytaty, wypowiedzi są wykorzystywane przez serwisy plotkarskie jako ilustracje coraz to nowych komentarzy, recenzji i spekulacji. Na skutek ,pasożytowania” na innych mediach serwisy plotkarskie nie wchodzą w bezpośrednie interakcje, a więc również relacje wzajemności z celebrytami. Stanowi to poważny problem dla tych $\mathrm{z}$ nich, którzy chcą kontrolować przebieg własnej trajektorii.

Serwisy plotkarskie stosują wreszcie głębokie ramowanie, konstruując dość dowolne ramy opisywanych zdarzeń z pozornie neutralnych elementów. Najlepszym przykładem tego zjawiska jest artykuł opisujący zakup choinki przez Martę Kaczyńską i jej męża. Główną część informacji stanowi 6 zdjęć ukazujących Martę Kaczyńską, jej męża i dzieci w typowym punkcie sprzedaży choinek. Na zdjęciach nie widać interakcji między bohaterami, trudno również jednoznacznie przypisać im jakieś emocje. Rama interpretacji narzucona przez Plotka jest jednoznaczna. Już sam tytuł: „Kaczyńska i Dubieniecki: spór o choinkę” definiuje sytuację. Do neutralnych zdjęć redaktorzy serwisu dodali podpisy, które konstruują narrację kłótni w rodzinie. Dodatkowo zdjęcia są kadrowane i łączone tak by budować wrażenie interakcji między ukazywanymi na nich osobami. Z podpisów czytelnicy Plotka dowiadują się, że „stojący z tyłu Dubieniecki zdaje się nie podzielać [...] entuzjazmu..." rodziny, później „burza nadchodzi” i „Kaczyńska ma dość głupich pomysłów męża. Jak może upierać się przy tak małej choince?” Z ostatniego "slajdu” czytelnicy dowiadują się jednak, że owa „mała choinka” została jednak zakupiona. Plotek mógł zatem ukazać to wydarzenie jako sielankową scenę przedświątecznego zakupu tradycyjnego drzewka. Dlaczego nałożono na nie ramę konfliktu? Obraz konfliktu w rodzinie Kaczyńskich jest bardziej wiarygodny niż obraz sielanki, wszak serwisy plotkarskie pisały o nim w przypadku Marty Kaczyńskiej aż 32 razy.

Jak już wspomniano, surowcem z których Plotek i Pudelek „klecą” celebrytów są najczęściej pseudowydarzenia skonstruowane na użytek innych mediów: występy w „Tańcu z Gwiazdami”, aranżowane sesje zdjęciowe w pismach kolorowych czy blogowe kreacje. Elementy tych gotowych symulakrów są dość swobodnie selekcjonowane i reorganizowane przez serwisy plotkarskie. Specyfika konsumowania treści w tego rodzaju portalach sprawia, że swobody tej nie ograniczają niespójności, sprzeczności i różnice między kreowanymi obrazami. Z tych wszystkich powodów internetowe serwisy plotkarskie uznać można za ostateczne medium celebrytyzacji, w którym hiperrzeczywistość produkowana jest 
poza kontrolą jej głównych bohaterów - celebrytów. Ta własność ma szczególnie istotne znaczenie w kontekście relatywnego spadku znaczenia tradycyjnych mediów, w których proces celebrytyzacji jest negocjowany, a więc również pozostaje pod większą kontrolą politycznych celebrytów.

\section{Bibliografia}

Annusewicz O., Celebrytyzacja polityczna, „Studia Politologiczne” 2011, vol. 20, s. $268-278$.

Boorstin D. J., The image: a guide to pseudo-events in America, Harper \& Row, Publishers, New York 1964.

Currid-Halkett E., Starstruck: the business of celebrity, $1^{\text {st }}$ ed., Faber and Faber, New York 2010.

Cwalina W., Marketing polityczny: perspektywa psychologiczna, Gdańskie Wydawnictwo Psychologiczne, Gdańsk 2005.

Garapich A., Wpatrzeni w gwiazdy, „Press” 2008, nr 155, s. 76-78.

Godzic W., Znani z tego, że sq znani: celebryci w kulturze tabloidów, Wydawnictwa Akademickie i Profesjonalne: TVN, Warszawa 2007.

Goffman E., Człowiek w teatrze życia codziennego, Państwowy Instytut Wydawniczy, Warszawa 1981.

Maliszewski N., Jak zaprogramować wyborcę?, Centrum Doradztwa i Informacji „Difin", Warszawa 2008.

Marshall P. D., Celebrity and power: fame in contemporary culture, University of Minnesota Press, Minneapolis Minn 1997.

Marwick A., d. boyd, To See and Be Seen: Celebrity Practice on Twitter, „Convergence: The International Journal of Research into New Media Technologies”, vol. 17, no. 2, s. 139-158, maj 2011.

Mills C. W., Elita władzy, Książka i Wiedza, Warszawa 1961.

Mrozowski M., Bohater naszych czasów, „Kultura Popularna” 2004, nr 3, s. 78-83.

Niczewski R., Celebryci w ataku: celebrity effect jako skuteczne narzędzie komunikacji marketingowej, Agora, Warszawa 2010.

Olczyk T., Przywódca czy celebrity? Strategie kreowania wizerunku w reklamie politycznej, w: Gra w przywództwo - jak zdobyć i utrzymać władzę, red. B. Szklarski, Ed. Collegium Civitas Press, Centrum Kreowania Liderów, 2008.

Olczyk T., Politrozrywka i popperswazja: reklama telewizyjna w polskich kampaniach wyborczych XXI wieku, Wydawnictwa Akademickie i Profesjonalne, Warszawa 2009. 
Olczyk T., Widmo postpolityzmu, w: M. Białecki i in., Platforma Obywatelska. Diagnoza, Klub Badań nad Propaganda, Warszawa 2011.

Piontek D., Komunikowanie polityczne i kultura popularna: tabloidyzacja informacji o polityce, Wydawnictwo Naukowe WNPiD UAM, Poznań 2011.

Rein I. J., High visibility, $1^{\text {st }}$ ed., Dodd, Mead, New York 1987.

Street J., Celebrity Politicians: Popular Culture and Political Representation, „British Journal of Politics \& International Relations" 2004, nr 6, s. 435-452.

West D. M., Orman J. M., Celebrity Politics, $1^{\text {st }}$ ed., Prentice Hall, 2002.

\title{
The theory and practice of political celebritization. Political celebrities in Internet gossip websites
}

\begin{abstract}
Summary
Celebrities are becoming a subject of growing interest for researchers and journalists. Studies on fame and popularity have become a separate research field with its own academic periodical. There are emerging books devoted solely to celebrities in the world of politics discussing the phenomenon of the increasing role of fame in modern politics, given the context of tabloidization, post-politics or the 'entertainization' of politics. Although the corpus of literature dealing with studies on political celebrities is increasing, this field continues to struggle with at least two fundamental issues. The first difficulty concerns the operational application of the concept of celebrity to describe the realm of politics. The second one concerns the limited number of empirical analyses of the phenomenon of political celebritization.

The aim of this paper is to begin to fill this gap. The first part analyzes terminological difficulties concerning the concept of political celebrity. Next, the author suggests a new approach to this concept.
\end{abstract}

